A significant association was noted between educational status and, religious beliefs $(p=0.001)$, lack of trust in the pharmaceutical laboratories $(p=0.007)$, fear that the vaccine would make RA worse $(p=0.008)$ or interact with other treatments $(p=0.022)$, and presumed overprice of vaccine $(p<0.001)$.

Conclusion: Most of RA patients expressed their unwillingness to get vaccinated against covid-19. Doubts about the vaccine's efficiency and security and religious beliefs were the main reasons for this choice.

Disclosure of Interests: None declared

DOI: 10.1136/annrheumdis-2021-eular.3667

\section{AB0699 RETROSPECTIVE ANALYSIS OF 52 SARS-COV2 POSITIVE PATIENTS WITH INFLAMMATORY RHEUMATIC DISEASE: A SINGLE CENTER EXPERIENCE}

Y. Karabulut ${ }^{1}{ }^{1}$ Private Yıldırım Doruk Hospital, Division of Rheumatology, Bursa, Turkey

Background: It is a generally accepted opinion that autoimmune and inflammatory rheumatic diseases or drugs used in the treatment of these conditions increase the risk of infection. During the pandemic period, the follow-up and treatment of patients who were diagnosed with rheumatic disease and used corticosteroid, immunosuppressive, biological or synthetic DMARDs and disease management during sars-cov2 infection still remain a problem.

Objectives: In this study, it was aimed to share the demographic data of 52 patients with inflammatory rheumatic disease diagnosed with SARS-COV2 who were followed up and treated in the Rheumatology Department of Private Doruk Hospital during the SARS-COV2 pandemic. Additionally, it is aimed to examine the primary rheumatological diseases of the patients, their biological and conventional DMARD treatments, their comorbidities and the course of SARS-COV2.

Methods: Fifty-two patients who were diagnosed with SARS-COV2 by PCR method while being followed up and treated in the rheumatology center between May 2020 and November 2020 and get COVID treatment in the same center were included in the study. All patients diagnosed with SARS-COV2 and required hospitalization were hospitalized in the same center and followed up and treated. The files and electronic records of the patients were retrospectively recorded by the rheumatologist who followed the patients.

Results: In this retrospective study conducted from a single center, 52 patients whose diagnosis of SARS-COV2 was confirmed by PCR were included. Distribution of primary rheumatic diseases of the patients; 19 rheumatoid arthritis (RA), 14 Ankylosing spondylitis (AS), 4 Psoriatic Arthritis (PsA), 4 Systemic lupus erythematosus (SLE), 5 Behcet's Disease (BD), 4 Familial Mediterranean Fever (FMF), 2 Sjögren's syndrome. $76.8 \%$ of the patients were female, $22.2 \%$ male, their mean age was $47 \pm 18$. Biological drug use rate of 37 patients in RA, AS and PsA groups was $83.7 \%$ (monotherapy or combination 31/37).

Moreover, $16.2 \%(6 / 37)$ of the patients were using synthetic DMARD combination (MTX+SLZ $+\mathrm{HCQ}$ ) and $40.5 \%(15 / 37)$ of the patients were using a combination of biological and synthetic DMARDs. While $73 \%(38 / 52)$ of 52 patients had a mild course, 27\% (14/52) had severe SARS-COV2 requiring hospitalization. 14 patients who had severe SARS-COV2 infection and required hospitalization, 10 were followed up with the diagnosis of RA, 2 with AS and 2 with SLE. Hospitalization of patients using monotherapy biological drugs (TNF inhibitor, Tocilizumab, IL 17-A) due to severe SARS-COV2 was found to be lower than the group using combined synthetic DMARDs with steroids $(\mathrm{MTX}+\mathrm{SSZ}+\mathrm{HCQ})(\mathrm{p}<0.05)$. The corticosteroid dose of the RA patients was in the range of $5-10 \mathrm{mg} / \mathrm{day}$. The rate of having severe SARS-COV2 was found to be higher in the combination group using biological or synthetic DMARD and low dose corticosteroids compared to group using monotherapy biologicals $(p<0.05)$. The rate of having severe SARSCOV2 was found to be significantly higher in the group using 10/mg or more at the time of diagnosis $(p<0.05)$. Two patients with SLE multiple organ involvement had severe SARS-COV2 while using rituximab, and hospitalization was required. In terms of comorbidities, hypertension was the most common comorbidity with $64.2 \%(9 / 14)$ in the group with severe SARS-COV2, followed by obesity with $21.4 \%(3 / 14)$

Conclusion: In patients with inflammatory rheumatic disease, SARS-COV-2 infection and the drugs used for the treatment of primary disease are still considered to be a difficult situation in terms of prognosis. In our study with limited cases, data suggesting that there is no increased risk of SARS-COV2 requiring hospitalization in patients using TNF inhibitors, tocilizumab and IL17-A blockers. It was thought that there might be a drug-induced increased risk due to the severe SARS-COV2 infection that developed in our two patients who used rituximab, but the disease-related risk increase was not ignored because the patients were SLE patients with active multi-organ involvement.

Disclosure of Interests: None declared

DOI: 10.1136/annrheumdis-2021-eular.3672

\section{$\mathrm{AB} 0700$ TOCILIZUMAB DID NOT REDUCE MORTALITY IN SEVERE COVID-19 PATIENTS BUT CAUSED THROMBOCYTOSIS}

Z. Öztürk ${ }^{1}$, S. M. Türk ${ }^{1}$, D. Karataș ${ }^{1}$, Ü. Erkorkmaz ${ }^{2}$, K. Özmen Süner ${ }^{3}$, H. Dheir ${ }^{4}$, E. Güçlü ${ }^{5}$, E. Gönüllü ${ }^{1}$, O. Karabay ${ }^{5}$. ${ }^{1}$ Sakarya University Training and Research Hospital, Rheumatolojı, Adapazarı, Turkey; ${ }^{2}$ Sakarya University Training and Research Hospital, Biostatistics, Adapazarı, Turkey; ${ }^{3}$ Sakarya University Training and Research Hospital, Anesthesia, Adapazarı, Turkey; ${ }^{4}$ Sakarya University Training and Research Hospital, Nephrology, Adapazarl, Turkey; ${ }^{5}$ Sakarya University Training and Research Hospital, Infectious Diseases and Microbiology, Adapazarı, Turkey

Background: TCZ is a monoclonal antibody against Interleukin-6 receptor (IL$6 \mathrm{R})$ which is used for relieving inflammation and reducing mortality in COVID 19 patients. Safety and efficacy of Tocilizumab (TCZ) in Covid-19 pneumonia is uncertain yet. In this study, we aimed to determine clinical outcomes in patients treated with $\mathrm{TCZ}$

Objectives: In this study we aimed to share our retrospective results which we had obtained from patients with COVID-19 diagnosis received TCZ.

Methods: We performed a retrospective case control study between May and August 2020 in Turkey. We compared outcomes in patients who received TCZ with those who did not. Death in hospital and intensive care unit (ICU) requirements were evaluated as endpoints. Demographic data, comorbidities, additional treatment, treatment side effects, laboratory and clinical results were retrospectively assessed. There are no significant differences between groups according to age, gender and Charlson Comorbidity Index (CCl).

Results: 12 (27.3\%) patients died in standard group and eight (18.6\%) patients died in TCZ group ( $p=0.150)$.Days of staying in the hospital were eight days in standard treatment group and 12 days in TCZ group $(p=0.03) .10$ of 43 patients in TCZ group were admitted to ICU. MV support was needed in 8 of these patients. 18 of 44 patients $(40.9 \%)$ within the standard group were admitted to ICU and 12 patients $(27.3 \%)$ were intubated $(p=0.125, p=0.480)$. Significant IL-6 decrease was not observed post treatment in TCZ group according to pretreatment period $(p=0.60)$. Significant decreases were examined in CRP and ferritin values through TCZ treatment. However, D-dimer and thrombocyte values increased.

Conclusion: TCZ may not be an effective treatment for reducing ICU requirement, to prevent intubation or death, for shortening period for staying in hospital. The patients should be followed up closely for possible thrombosis because of increased D-dimer and thrombocytes with TCZ treatment.

\section{REFERENCES:}

[1] Sharma A, Tiwari S, Deb MK, Marty JL. Severe acute respiratory syndrome coronavirus-2 (SARS-Cov-2): A global pandemic and treatment strategies. IntJ Antimicrob Agents. 2020 Aug; 56(2):106054.

[2] Singhal T. A rewiev of coronavirus Disease-2019(COVID-19). Indian J Pediatr. $2020 \mathrm{Apr} ; 87(4): 281-286$.

[3] Mehta P, McAuley DF, Brown M, Sanchez E, Tattersall R.S, Manson J.J. COVID-19: consider cytokine storm syndromes and immunosuppression. Lancet. 2020;395(10229):1033-

[4] Teijaro J.R. Cytokine storms in infectious diseases. Seminlmmunopathol. 2017;39:501-503.

[5] Zhang Y, Li J, Zhan Y, Wu L, Yu X, Zhang W et al. Analysis of Serum Cytokines in Patients with Severe Acute Respiratory Syndrome. Infect Immun 2004 Aug;72(8):4410-4415.

[6] Zhang C, Wu Z, Li JW, Zhao H, Wang GQ. Cytokine release syndrome in severe COVID-19: interleukin-6 receptor antagonist tocilizumab may be the key to reduce mortality. Int J Antimicrob Agents. 2020 May; 55(5):105954.

[7] Xu Z, Shi L, Wang Y, Zhang J, Huang L, Zhang $C$ et al. Pathological findings of COVID-19 associated with acute respiratory distress syndrome. Lancet Respir Med. 2020;8(4):420-2

[8] Fu B, Xu X, Wei H. Why tocilizumab could be an effective treatment for severe COVID-19? J TransI Med 18,164 (2020)

[9] Guaraldi G, Meschiari M, Cozzi-Lepri A, Milic J, Tonelli R, Menozzi M et al. Tocilizumab in patients with severe COVID-19: a retrospective cohort study. Lancet Rheumatol. 2020 Aug;2(8):e474-e484.

[10] Gupta S, Wang W, Hayek S.S, Chan L, MathewsK.S, Melamed M.L et al. Association Between Early Treatment With Tocilizumab and Mortality Among Critically III Patients With COVID-19. JAMA Intern Med. 2021 Jan1;181(1):41-51.

[11] Campochiaro C, Della-Torre E, Cavalli G, De Luca G, Ripa M, Boffini N et al Efficacy and safety of tocilizumab in severe COVID- 19 patients: a single-centre retrospective cohort study. Eur J Intern Med. 2020 Jun;76:43-49.

Disclosure of Interests: None declared

DOI: 10.1136/annrheumdis-2021-eular.3697 